\title{
Pitfalls in the histological diagnosis of inflammatory bowel disease on colorectal biopsies
}

DA MALATJALIAN, MD

\begin{abstract}
Histopathological examination of appropriate colorectal biopsy specimens allows accurate identification of chronic inflammatory bowel disease in the majority of cases. Pitfalls, however, appear because overlapping histological features occur among the various forms of colitis or because a specific form of colitis may exhibit incomplete expression of its characteristic features. Pitfalls can be minimized if the histological findings are considered in the context of all other clinical and investigative data. Can J Gastroenterol 1990;4(7):336-340
\end{abstract}

Key Words: Histological diagnosis, Inflammatory bowel disease, Pathology

\section{Ecueils dans le diagnostic histologique des maladies inflam- matoires de l'intestin d'après les biopsies colorectales}

RESUME: L'examen histopathologique des prélèvements biopsiques colorectaux permet de diagnostiquer correctement la majorité des cas d'entéropathies inflammatoires chroniques. Les erreurs surviennent toutefois, à cause du chevauchement des caractéristiques histologiques que partagent diverses formes de colites ou parce que certains types de colite ne manifestent qu'une partie de leurs caractéristiques propres. Il est toutefois possible de minimiser ces écueils si les résultats histologiques sont examinés dans le contexte de toutes les autres données cliniques et de la recherche.

Victoria General Hospital, Halifax, Nova Scotia

Correspondence and reprints: Dr DA Malatjalian, Victoria General Hospital, 1278 Tower Road, Halifax, Nova Scotia B3H 2 Y9
T HE TERM INFLAMMATORY BOWEL, disease (IBD) conventionally refers to ulcerative colitis and Crohn's disease, both of which are of uncertain etiology and run a chronic course $(1,2)$. There are other forms of colitis which can mimic IBD clinically, endoscopically and radiologically (Table 1). Most of these have specific etiologies and their differentiation from IBD is of

\section{TABLE 1}

\section{Differential diagnosis of colitis}

Inflammatory bowel disease Acute self-limited colitis

Pseudomembranous colitis Ischemic colitis

Parasitic infections

Amebiasis

Schistosomiasis

Drug-induced colitis

Radiation colitis

Solitary rectal ulcer syndrome

Behçet's syndrome

Microscopic and collagenous colitis Other 
TABLE 2

Causes of pitfalls in the histological evaluation of colorectal biopsies in colitis

Limited morphological expression of

inflammation $\rightarrow$ Overlapping

histological features

incomplete expression of response to disease $\rightarrow$ Absence of discriminating histological features

Lack of pathognomonic changes

Occurrence of 'indeterminate colitis'

great therapeutic and prognostic significance.

Histological evaluation of colorectal mucosal biopsy specimens is an important parameter in the evaluation and management of patients with colitis (37). Biopsies are of value when there is a clinical need to confirm the presence or absence of IBD, to recognize other forms of colitis, to distinguish between ulcerative colitis and Crohn's disease, to determine the extent of disease and to detect dysplasia and carcinoma which may complicate longstanding IBD.

While the histopathological features of IBD are characteristic,

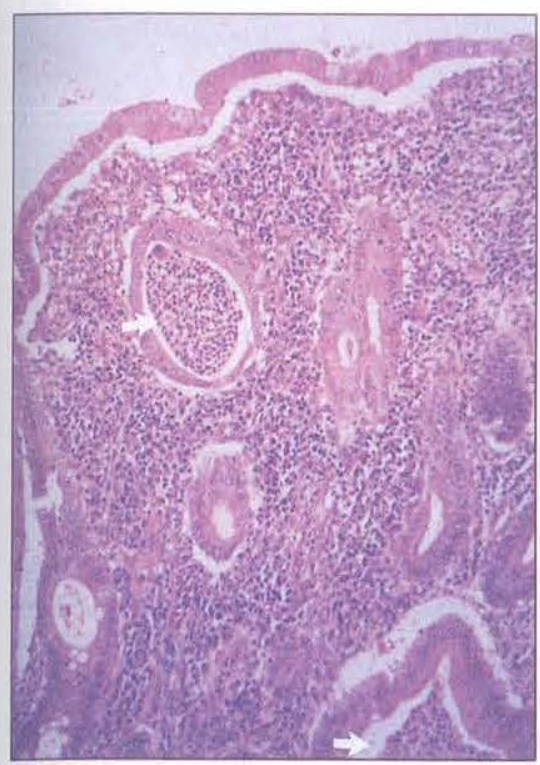

Figure 1) Rectal mucosal biopsy from a patient with ulcerative proctitis. Note the heavy mononuclear inflammatory cell infiltrate in the lamina propria, the irregularity of crypt architecture, the depletion of goblet cell mucin and the crypt abscesses (arrows). Irregularity of crypt architecture is highly characteristic of inflammatory bowel disease, especially ulcerative colitis
TABLE 3

Acute self-limited colitis (ASLC) versus inflammatory bowel disease (IBD) (distinguishing features in colorectal biopsies)

\begin{tabular}{lll}
\hline & ASLC & IBD \\
\hline Crypt abscesses & Superficial & Transmucosal \\
Goblet mucus depletion & Mild & Marked \\
Inflammatory infiltrate & Polymorphonuclearleukocytes & Mononuclear cells \\
Pseudovillous mucosa & Absent & Present \\
Crypt architecture & Preserved & Distorted \\
Crypt atrophy & Absent & Present \\
Paneth cell metaplasia & Absent & Present \\
Epithelioid granulomas & Absent & Crohn's disease \\
\hline
\end{tabular}

problems leading to pitfalls may occur in the histological differentiation between IBD and other forms of colitis on one hand, and between ulcerative colitis and Crohn's disease on the other (Table 2). Difficulties often orcur because the colon possesses limited morphological expression of inflammatory responses which often shows overlap among a variety of conditions. In addition, a specific type of colitis may exhibit incomplete expression of its characteristic histological features, rendering it difficult to recognize. Difficulties also arise because of the occurrence of indeterminate colitis with overlapping histological findings, which may be impossible to diagnose accurately.
Two conditions often considered in the differential diagnosis of patients with acute onset colitis are IBD and acute self-limited colitis (ASLC) $(8,9)$. ASLC refers to acute transient colitis caused by a known bacterial agent (infectious colitis) and colitides where no enteropathogenic microorganisms are identified on stool culture, but by all other criteria would be considered acute infectious-type colitis. Acute onset IBD may be indistinguishable clinically from ASLC. Conversely, severe forms of ASLC can mimic IBD even to the extent of causing toxic dilation of the colon. The histological differentiation between IBD and ASLC is, therefore, of considerable importance (Table 3).

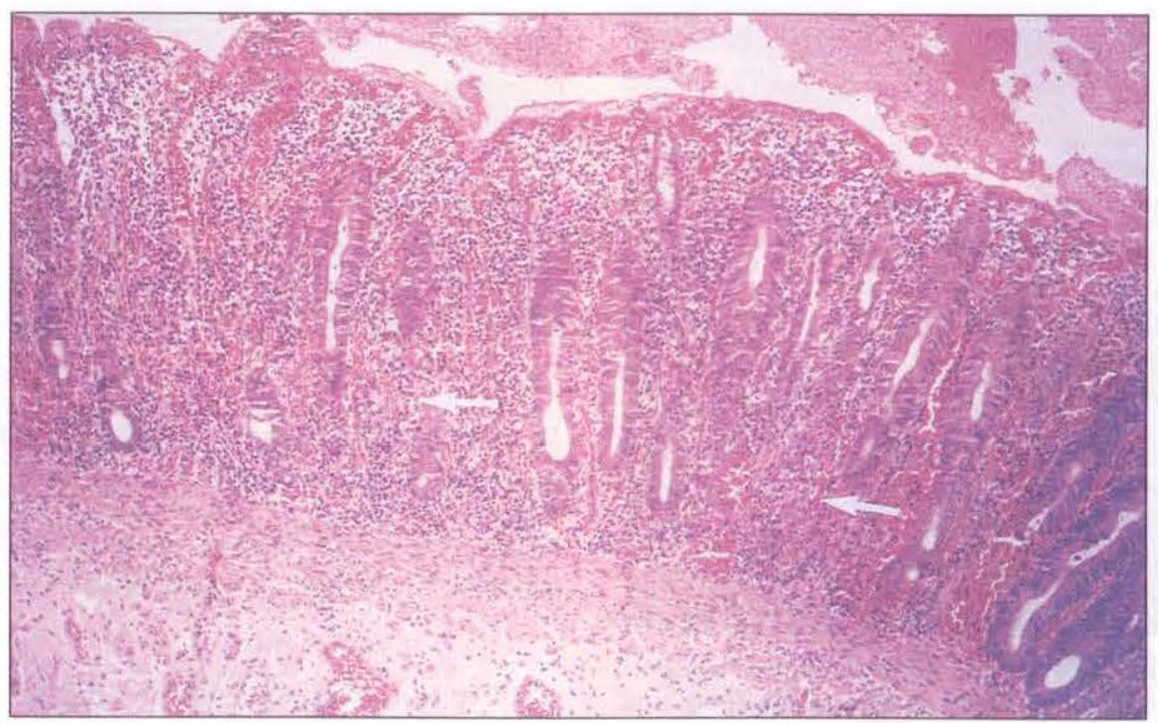

Figure 2) Rectal mucosal biopsy from a patient with drug-induced (gold salt therapy for rheumatoid arthritis) acute colitis. As in Figure 1, there is marked goblet cell mucin depletion and focal cryptitis (arrow). In contrast to inflammatory bowel disease (Figure 1), the crypt architecture is well preserved. A repeat biopsy after withdrawal of the drug demonstrated entirely normal mucosa, a feature common to all forms of acute self-limited colitis 


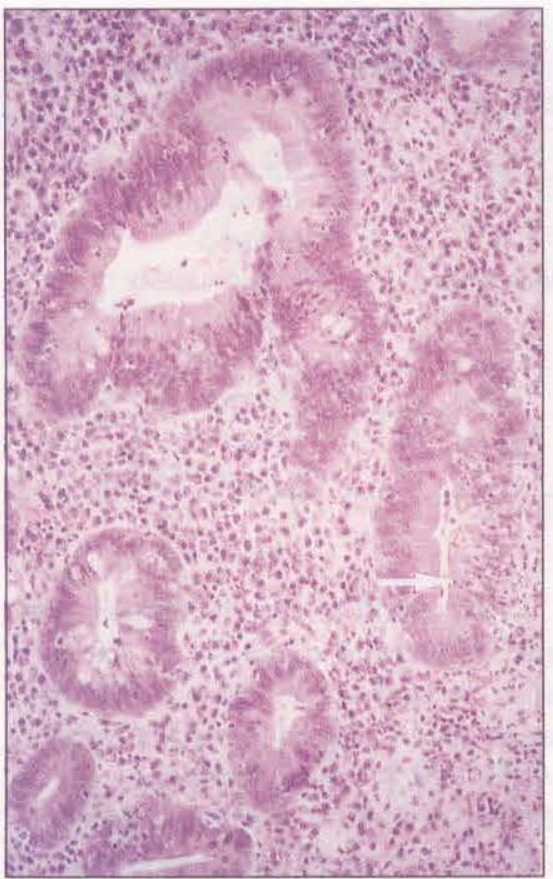

Figure 3) Colonic mucosal biopsy from a patient with ulcerative colitis. Note the heavy lymphocyte and plasma cell infiltrate in the lamina propria. The cryptitis is caused by polymorphonuclear cells (arrow). Also note distortion of normal crypt architecture

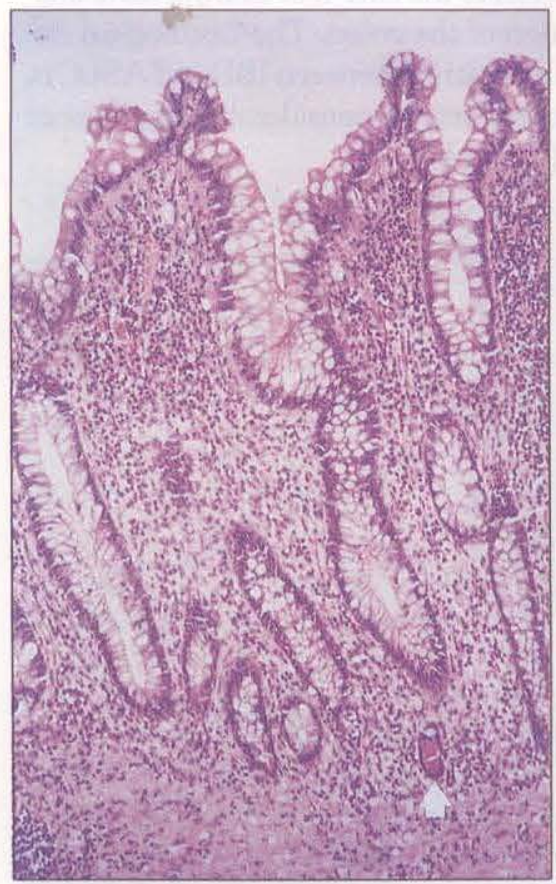

Figure 4) Colonic mucosal biopsy demonstrating the pseudovillous pattern of the mucosal surface. This is seen in about $20 \%$ of cases of inflammatory bowel disease and is a highly characteristic histological finding. It does not occur in acute self-limited colitis. Also note the heavy mononuclear cell infiltrate in the lamina propria and the focal Paneth cell metaplasia (arrow)

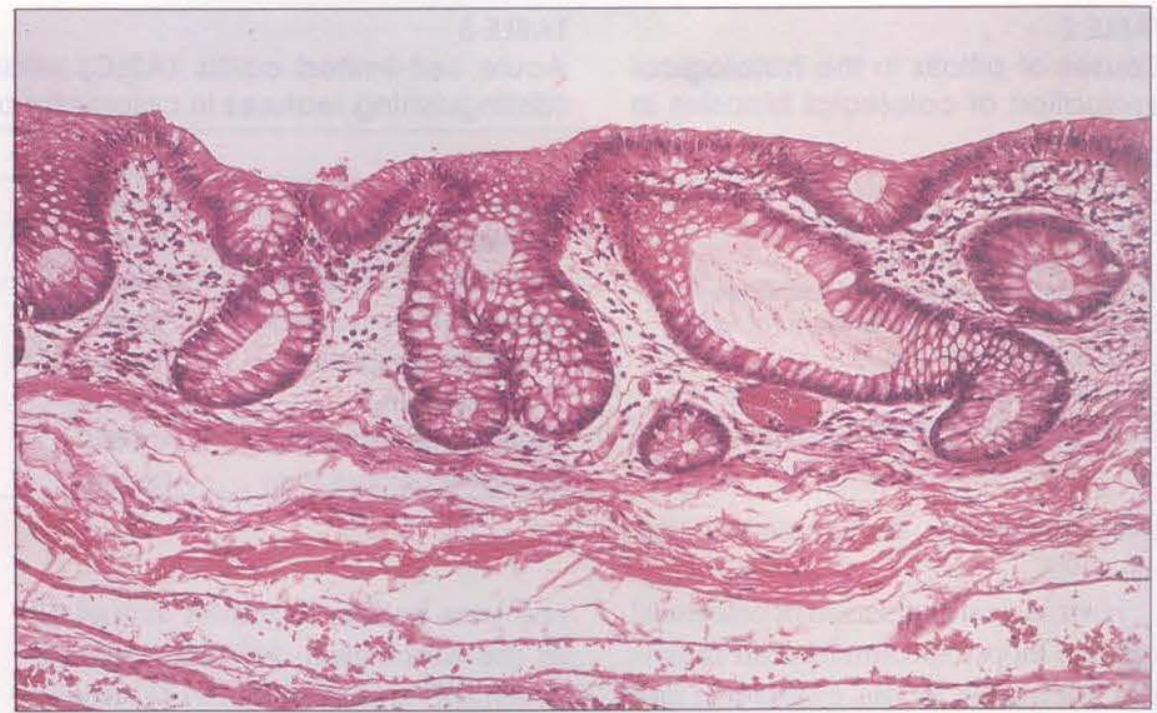

Figure 5) Colonic mucosa from a case of quiescent ulcerative colitis demonstrating mucosal atrophy, crypt distortion and focal Paneth cell metaplasia. Note sparse inflammatory cell infiltrate in the lamina propria. The absence of cryptitis and crypt abscesses are features of inactive ulcerative colitis

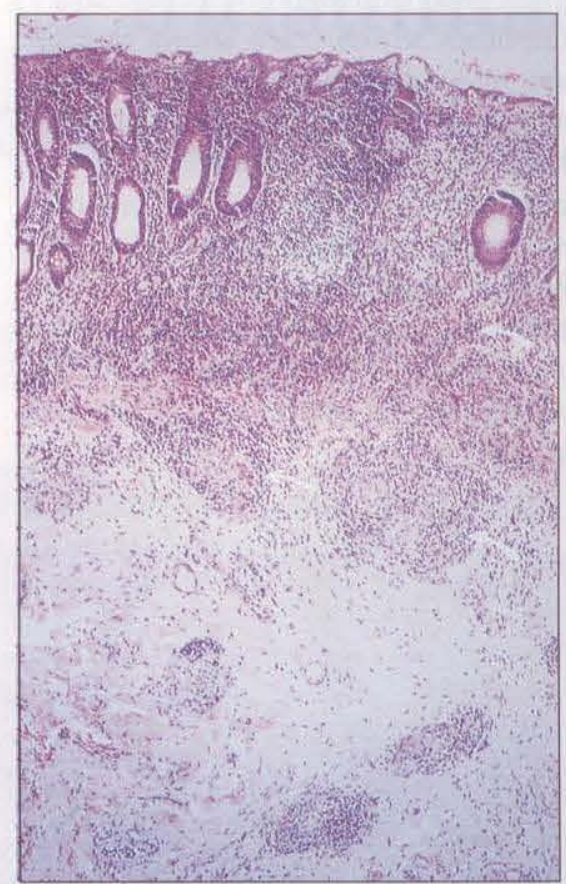

Figure 6) Colonic mucosal biopsy from a patient with Crohn's disease. Note the mucosal and submucosal epithelioid granulomas (arrows) and the presence of mucosal and submucosal mononuclear inflammatory cell infiltrate. The crypts appear relatively well preserved but their goblet cell mucin is depleted

Cryptitis, crypt abscesses and depletion of goblet cell mucin (Figures 1,2) are shared by all forms of acute or active colitis regardless of etiology. These nonspecific features are reversible upon recovery or during remission of the

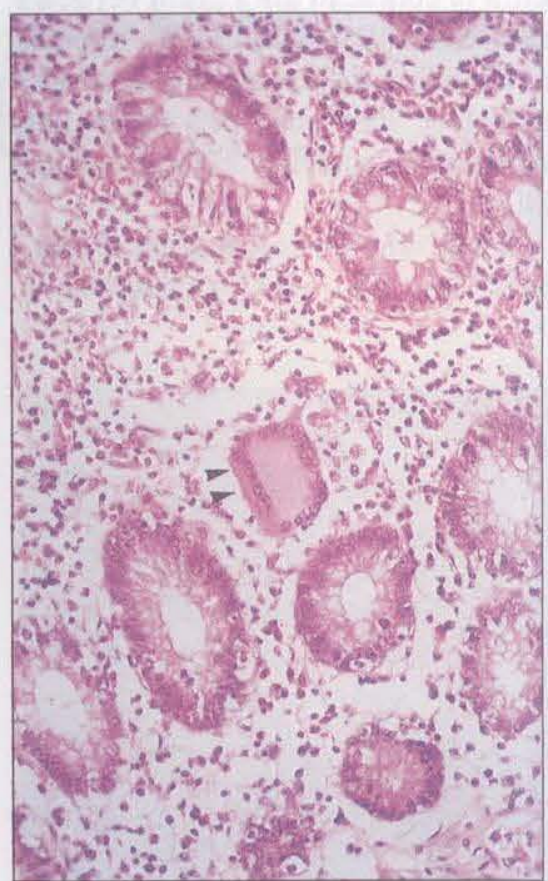

Figure 7) Colonic mucosal biopsy from a patient with Crohn's disease showing isolated intramucosal Langhans' giant cell (arrowheads)

colitis. On the other hand, there are characteristic histological features which help distinguish chronic IBD and ASLC. These include: predominantly lymphocytic infiltrate in the lamina propria (Figure 3); villiform (pseudovillous) pattern of the mucosal surface (Figure 4); distorted and/or atrophic crypts (Figure 5); Paneth cell 


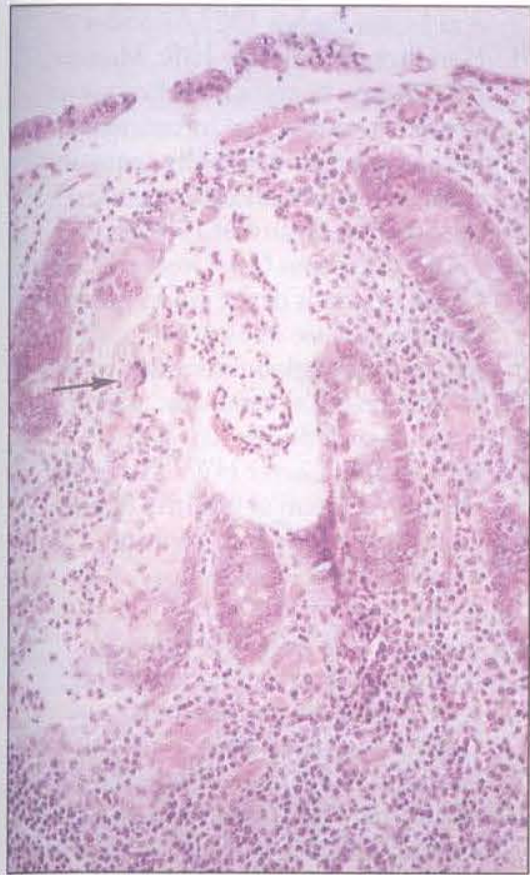

Figure 8) Foreign body granuloma with a multinucleated giant cell (arrow) in the superficial part of the mucosa from a patient with ulcerative colitis. These granulomas may cause confusion with Crohn's disease. In Crohn's disease, the characteristic epithelioid granulomas are found deep in the mucosa and submucosa (see Figure 6)

metaplasia (Figures 4,5); and epithelioid granulomas with or without Langhans' giant cells (Figures 6,7). These changes are typically absent in ASLC.

Since the above characteristic histopathological features of IBD are related to the chronicity of inflammation, they may be absent in the early stages of IBD, thus posing a problem in differentiating it from ASLC. When the histological findings are equivocal, examination of follow-up biopsies

taken six to eight weeks later may yield more diagnostic findings. If continued inflammation or crypt architectural abnormalities are found in follow-up biopsies, the diagnosis of IBD is established. On the other hand, if follow-up biopsies demonstrate normal mucosal histology, a diagnosis of ASLC would be more likely.

It is important to point out that while there are histological features characteristic of IBD, none of these is

\section{TABLE 4}

\section{Helpful features for distinguishing ulcerative colitis from Crohn's disease in} colorectal biopsies

\begin{tabular}{|c|c|c|}
\hline Features & Ulcerative colitis & Crohn's disease \\
\hline Inflammation & Diffuse, mucosal & $\begin{array}{l}\text { Patchy, mucosal and } \\
\text { submucosal }\end{array}$ \\
\hline Crypt abscesses & Frequent & Few \\
\hline Crypt distortion & Mild to severe & Mild \\
\hline Mucosal atrophy & Common & Rare and slight \\
\hline Goblet mucin depletion & Marked & Slight \\
\hline Paneth cell metaplasia & Common & Rare \\
\hline $\begin{array}{l}\text { Epithelioid granulomas and/or } \\
\text { Langhans' giant cells }\end{array}$ & Absent & Diagnostic \\
\hline
\end{tabular}

pathognomonic. Crypt distortion and Paneth cell metaplasia may also occur in other forms of chronic colitis such as ischemic colitis (10), radiation colitis and solitary rectal ulcer syndrome.

Epithelioid granulomas are sine qua non for the diagnosis of Crohn's disease (11-13). Unfortunately they are found in only about $15 \%$ of colorectal biopsies from patients with proven Crohn's disease. Less frequently isolated Langhans' giant cells, with the same diagnostic significance as epithelioid granulomas, may be found (Figure 7).

Epithelioid granulomas in Crohn's disease are characteristically found deep in the mucosa and submucosa and need to be differentiated from foreign body granulomas (Figures 8,9 ). The latter tend to occur superficially in the mucosa but occasionally in the submucosa. Foreign body granulomas may be found in ulcerative colitis, ASLC and other forms of colitis. Granulomas also occur in schistosomiasis and rarely in cryptococcosis (14).

The differentiation between ulcerative colitis and Crohn's disease is important because of therapeutic and prognostic implications (Table 4). While most patients can be categorized as having ulcerative colitis or Crohn's disease without difficulty, in some the distinction between the two conditions is uncertain. In such instances, colorectal biopsies may be of help, particularly when correlated with clinical, endoscopic and radiological findings. A normal biopsy as evidence of a spared rectum or other skip areas, patchy mucosal and submucosal inflammation and an epithelioid granuloma or Langhans' giant cell favour Crohn's colitis, whereas diffuse inflammation, marked goblet cell depletion and a significant degree of crypt destruction, crypt architectural distortion or atrophy suggest ulcerative colitis.

Aphthous ulcers in seemingly normal mucosa are a characteristic endoscopic feature of Crohn's disease and are believed to represent early lesions of Crohn's disease $(15,16)$. However, aphthous ulcers may occur in other forms of colitis including Behçet's syndrome (17) and amebiasis (18).

In about $7 \%$ of patients with acute 
fulminant colitis, differentiation between ulcerative colitis and Crohn's disease may not be possible even when a colectomy specimen becomes available for gross and microscopic examination. Such cases are best classified as 'indeterminate colitis' until subsequent clinical course and followup biopsies make a more precise classification possible (19).

In spite of certain limitations, microscopic examination of colorectal biopsies plays a major role in the diagnosis of colitis. To minimize pitfalls, the colorectal biopsy specimen should be appropriate and sectioned serially for a thorough microscopic examination (20). The histopathological findings need to be interpreted in the context of clinical and other investigative data.

\section{REFERENCES}

1. Tawile NT, Priest RJ, Schuman BM. Colonoscopy in inflammatory bowel disease. Gastrointest Endosc 1975;22:11-3.

2. Farmer RG. Inflammatory bowel disease. Clin Gastroenterol 1980;9:229. (Intro)

3. Gear EV Jr, Dobbins WO III.
Rectal biopsy: A review of its diagnostic usefulness. Gastroenterology 1968;55:522-44.

4. Morson BC. The technique and interpretation of rectal biopsies in inflammatory bowel disease. Pathol Annu 1974;9:209-30.

5. Goodman MJ, Kirsner J-B, Riddell RH. Usefulness of rectal biopsy in inflammatory bowel disease. Gastroenterology 1977;72:952-6.

6. Yardley JH, Donowitz M. Colo-rectal biopsy in inflammatory bowel disease. In: Yardley JH, Morson BC, Abell MR, eds. The Gastrointestinal Tract. Baltimore: Williams and Wilkins, 1977:50-94.

7. Whitehead R. Mucosal Biopsy of the Gastrointestinal Tract, 2nd edn. Philadelphia: WB Saunders, 1979.

8. Kumar NB, Nostrant TT, Appleman HD. The histopathologic spectrum of acute self-limiting colitis (acute infectious-type colitis). Am J Surg Pathol 1982;6:523-9.

9. Surawicz CM, Belic L. Rectal biopsy helps to distinguish acute self-limited colitis from idiopathic inflammatory bowel disease. Gastroenterology 1984;86:104-13.

10. Marston A. Intestinal Ischemia. Chicago: Year Book Medical Publishers Inc, 1977.

11. Morson BC. Pathology of Crohn's disease. Clin Gastroenterol 1972;1:265-77.

12. Rotterdam H, Korelitz BI, Sommers SC. Microgranulomas in grossly normal rectal mucosa in Crohn's disease.
Am J Clin Pathol 1977;67:550-4.

13. Hamilton SR, Bussey HJR, Morson BC. En face histologic technique to demonstrate mucosal inflammatory lesions in macroscopically uninvolved colon of Crohn's disease resection specimens. Lab Invest 1980;42:121.

14. Hutto JO, Bryan GS, Greene FL, et al. Cryptococcosis of the colon resembling Crohn's disease in a patient with the hyperimmunoglobulinemia E-recurrent infection (Job's) syndrome. Gastroenterology 1988;94:808-12.

15. Rickert RR, Carter HW. The 'early' ulcerative lesion of Crohn's disease: Correlative light and scanning electron microscopic study. J Clin Gastroenterol 1980;2:11.

16. Lusk LB, Reichen J, Levine JS. Aphthous ulceration in diversion colitis: Clinical implications. Gastroenterology 1984;87:171-3.

17. Lee RG. The colitis of Behçet's syndrome. Am J Surg Pathol 1986;10:888-93.

18. Tucker PC, Webster PD, Kilpatrick ZM. Amebic colitis mistaken for inflammatory bowel disease. Arch Intern Med 1975;135:681-5.

19. Price $A B$. Overlap in the spectrum of non-specific inflammatory bowel disease - 'Colitis indeterminate'. J Clin Pathol 1978;31:567-77.

20. Surawicz CM. Serial sectioning of a portion of a rectal biopsy detects more focal abnormalities. A prospective study of patients with inflammatory bowel disease. Dig Dis Sci 1982;27:434-6. 


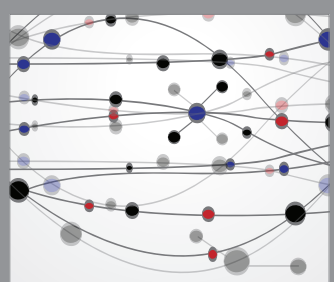

The Scientific World Journal
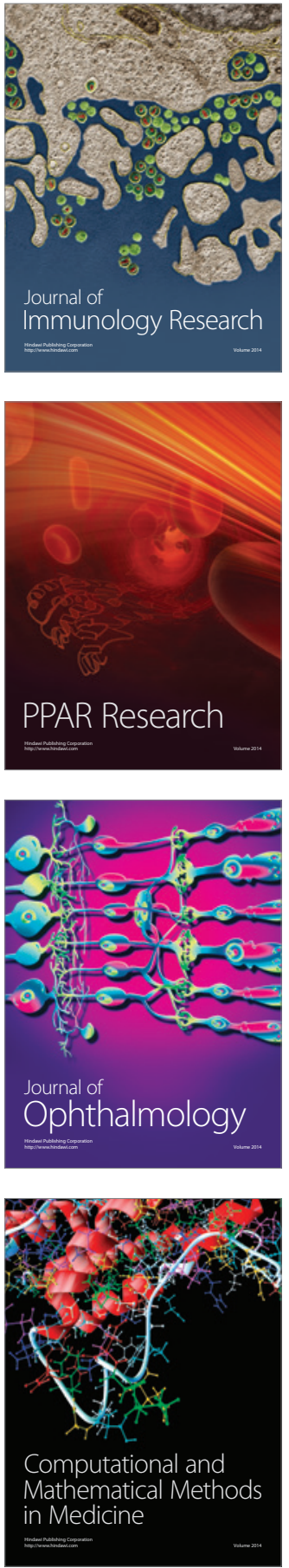

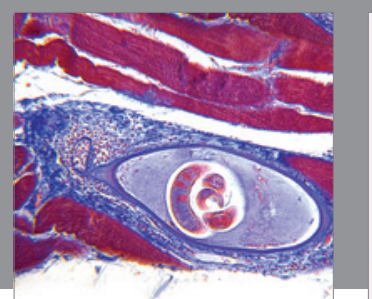

Gastroenterology Research and Practice

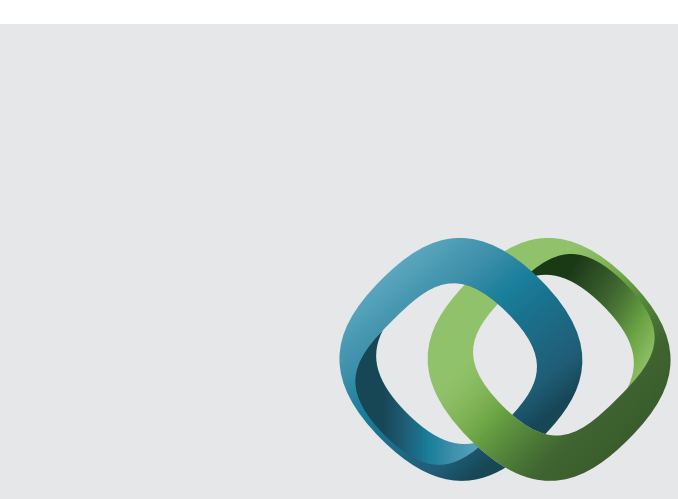

\section{Hindawi}

Submit your manuscripts at

http://www.hindawi.com
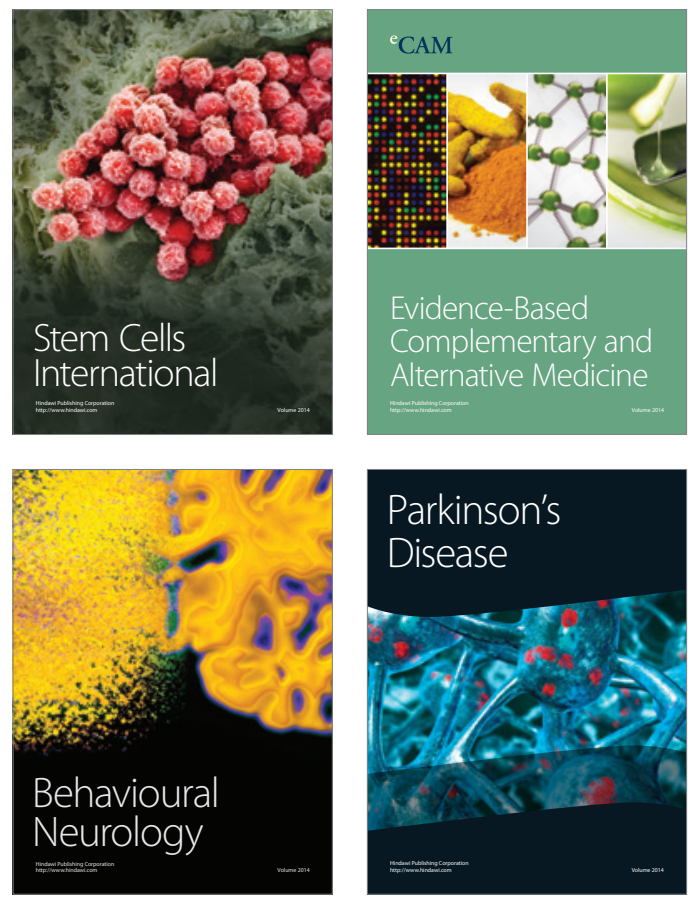
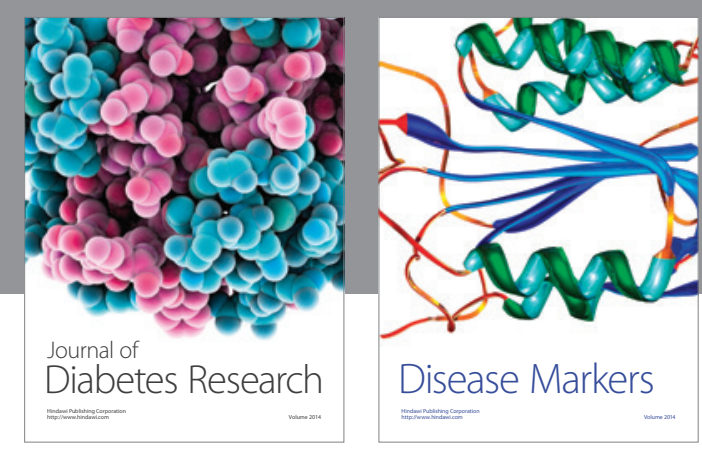

Disease Markers
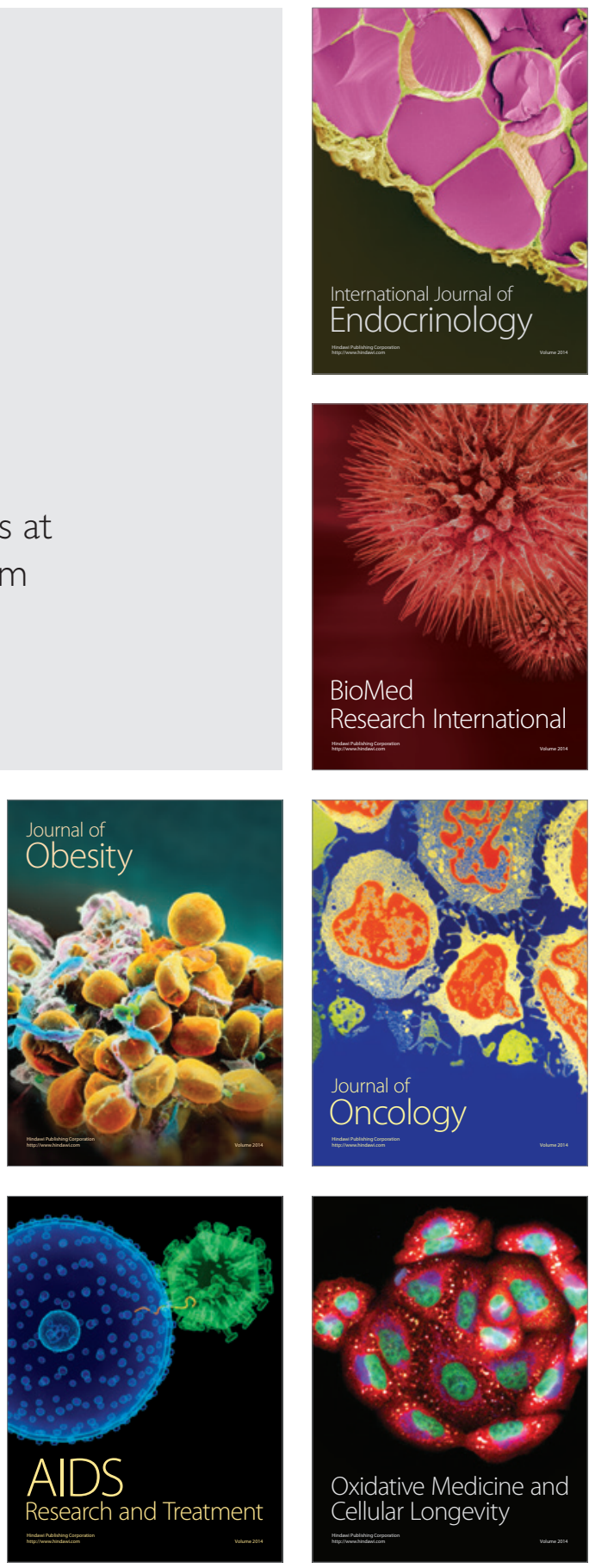